\title{
Processo para Construção de Réplicas em Mundos Virtuais para Aprendizagem Imersiva
}

\author{
Fábio Mariz Maia Pessoa ${ }^{1}$, Patrícia Cabral Azevedo Restelli Tedesco', Roberto de \\ Almeida Batista Ramos', Fábio Morais Borges ${ }^{2}$
}

${ }^{1}$ Centro de Informática - Universidade Federal de Pernambuco - UFPE

Av. Prof. Moares Rego, 1235 - Cidade Universitária. CEP 50670-901. Recife - PE - Brasil

${ }^{2}$ Departamento de Engenharia de Produção - Universidade Federal da Paraíba - UFPB

Cidade Universitária, S/N - CEP 58051-900 - João Pessoa - PB - Brasil

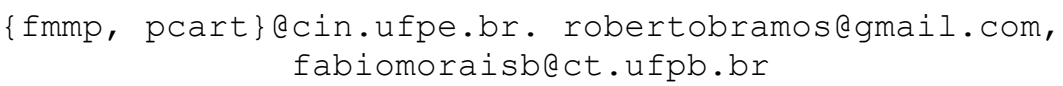

Abstract. The objective of this research is to describe a process to create replicas of real environments into virtual worlds, using immersive learning. In first sections, the concepts and benefits of the technologies used are presented. Then is presented the process model, focusing on fidelity to the real world. The process was instantiated by conducting an experiment and the results indicated increased student motivation as the final result.

Resumo. Este trabalho tem como objetivo apresentar um processo para a criação de réplicas de ambientes reais em mundos virtuais, para a prática da aprendizagem imersiva. Nas primeiras seções são apresentados os conceitos e beneficios das tecnologias utilizadas. Em seguida, é apresentado o modelo do processo, com foco na fidelidade do ambiente virtual em relação ao real. $O$ processo foi instanciado através da realização de um experimento e os resultados indicaram o aumento da motivação dos alunos como resultado final.

\section{Introdução}

O desenvolvimento da tecnologia tem permitido que instituições de ensino e organizações em geral desenvolvam cada vez mais soluções educacionais para ofertar cursos que independam de espaço físico, ou seja, implantando as modalidades de Educação a Distância (EAD) e mista.

Apesar do número crescente de soluções de EAD, as instituições de ensino que fornecem curso nesta modalidade ainda relatam algumas dificuldades, sobretudo no que diz respeito à motivação do aluno para a utilização de um ambiente de estudo virtual [CENSOEAD.BR 2013]. Para tentar mitigar essas dificuldades apresentadas, têm sido desenvolvidos estudos científicos no sentido de utilizar a Realidade Virtual na relação de ensino e aprendizagem - é a chamada aprendizagem imersiva [DEDE 2009]. 
Por outro lado, o desenvolvimento de um ambiente imersivo voltado para o ensino deve seguir uma série de etapas, visando, sobretudo, a garantir a fidelidade do ambiente construído com o mundo real, ou seja, assegurar o realismo gráfico. Tal realismo tem como finalidade auxiliar no aumento da motivação do aluno, e, como consequência, mitigar parte dos problemas relatados em EAD.

Nesse contexto, o objetivo deste trabalho é apresentar um processo específico para a construção de um ambiente imersivo voltado à prática docente em um mundo virtual. $\mathrm{O}$ processo foi instanciado, aplicado na prática e teve seus resultados avaliados.

Este artigo está estruturado da forma seguinte: a seção 2 aborda o conceito de aprendizagem imersiva, a motivação e a fidelidade ao ambiente real; a seção 3 discute o conceito de mundo virtual e aborda o mundo virtual utilizado nesta pesquisa; a seção 4 descreve o processo proposto, os atores, o ambiente replicado, as etapas a serem seguidas; e a análise qualitativa dos dados coletados a partir da aplicação de questionários quando da realização do experimento que validou o processo.

\section{Aprendizagem Imersiva}

Imersão é "a impressão subjetiva de que se está participando de uma experiência abrangente e realista" [DEDE 2009]. Numa concepção técnica, imersão é a característica capaz de gerar estímulos sensoriais verossímeis, e compreende a sensação de presença que o ser humano possui ao utilizar uma ferramenta imersiva [SLATER e WILBUR 1997].

Neste sentido, a aprendizagem imersiva se utiliza de técnicas que modelam situações práticas do mundo real para o virtual com o objetivo de transmitir conhecimento utilizando simulações e usando conteúdo baseado em resolução de problemas. Por isso, pode-se concluir que aprendizagem imersiva é a técnica que utiliza conceitos computacionais, notadamente a Realidade Virtual, para a prática docente.

Neste ponto, importante ressaltar a diferença entre imersão mental da imersão física. A primeira refere-se a quão envolvido um usuário está dentro de um ambiente de realidade virtual [SHERMAN e CRAIG 2003]; é, portanto, o estado em que o indivíduo se encontra envolvido pelos recursos de uma ferramenta computacional. A imersão física, por outro lado, envolve dispositivos táteis, auditivos ou visuais como luvas, capacetes, óculos e outros dispositivos sensoriais. Este estudo tem como fundamento a aprendizagem com a característica de imersão mental, não tendo utilizado dispositivos sensoriais para a prática de atividades educacionais com realidade virtual.

Imersão é um conceito que decorre da interação e está diretamente relacionado à questão da motivação do aluno no ambiente [CHENEY e SANDERS 2011]. Por esta razão, a seção a seguir discute esse benefício apontado pela literatura quando da utilização de uma ferramenta imersiva para o desempenho de alguma tarefa educacional.

\subsection{Motivação no Contexto da Aprendizagem Imersiva}

A análise etimológica da palavra "motivação" diz que o vocábulo advém da palavra "motivo" e tem origem no latim: "movere" ou "motus", que significa deslocar, mudar de lugar. A palavra "motivo" é definida sob a ótica da movimentação do ser humano para 
realizar alguma tarefa, ao passo que motivação é o fator que determina e condiciona a conduta. No contexto da educação, a motivação é definida como uma força interna que leva o aluno a agir [BARATA 2006].

A literatura indica diversos estudos sobre o conceito de motivação. Um deles é o que resultou na criação da "flow theory" [CSIKSZENTMIHALYI e NAKAMURA 2009]. A teoria foi desenvolvida na década de 1960 quando, da análise de um grupo de artistas plásticos, percebeu-se que, enquanto eles estavam imersos no ambiente de trabalho, a atenção e motivação se faziam presentes. Por outro lado, quando não estavam pintando, perdia-se o interesse. Segundo esta teoria, para que o indivíduo alcance um estado em que se encontre plenamente envolvido na atividade, é necessário que haja um equilíbrio entre os desafios fornecidos e as habilidades inerentes à pessoa.

Neste sentido, uma atividade que contenha diversos elementos desafiadores mas que não permita que o sujeito desenvolva suas habilidades, resulta em ansiedade por parte do usuário. Por outro lado, uma atividade em que o sujeito possa desenvolver suas habilidades mas que não se mostre desafiadora, tende a ser entediante.

É nesse estado de maior envolvimento do indivíduo - denominado "estado de flow" - onde ocorre o melhor aproveitamento da atividade que está sendo desempenhada. Aplicando a teoria de flow no contexto da tecnologia em educação, as ferramentas devem ter características que explorem as habilidades do aluno ao mesmo tempo em que as atividades devem conter elementos desafiadores, com o objetivo de proporcionar maior aprendizado.

Por outro lado, a literatura destaca que diversos fatores compõem a motivação do aluno em um ambiente imersivo. Em outras palavras, a aprendizagem imersiva traz ganhos na motivação por ter as seguintes características: fidelidade ao ambiente real [DE FREITAS e OLIVER 2006], relevância da lição no mundo real [CLARK 2010], interação, múltiplas perspectivas [DEDE 2009]. Este estudo tem como foco a característica da fidelidade ao ambiente real como recurso motivador na aprendizagem imersiva.

\subsection{Fidelidade ao Ambiente Real}

No contexto da aprendizagem imersiva, o aspecto da fidelidade de um ambiente virtual em relação ao real é importante na medida em que determina o grau de imersão mental do usuário [DE FREITAS e OLIVER 2006]. Isto é, quanto menos recursos que proporcionem realismo o ambiente virtual possuir, menor é a sensação de imersão do usuário. Por outro lado, quanto maiores os detalhes e o apelo gráfico, maior é a sensação de imersão.

Um ambiente virtual, para ser considerado imersivo, deve replicar todos os objetos constantes do ambiente real: os internos, que são aqueles cujo habitat é, de fato, o ambiente; bem como os externos, que são aqueles objetos que estão no ambiente em determinado momento mas que não fazem parte de fato daquele lugar [DE FREITAS e OLIVER 2006]. Por exemplo, o livro é um objeto interno de uma biblioteca. Por outro lado, é objeto externo de um quarto, ou seja, o habitat do livro não é o quarto, mas a biblioteca. 
Como visto, a aprendizagem imersiva proporciona ganhos em diversos fatores. Contudo, para sua materialização, é necessário que haja técnicas computacionais aliadas a recursos gráficos tridimensionais. Neste sentido, a seção a seguir discutirá o conceito de mundo virtual como instrumento para representação de um determinado ambiente no contexto da educação.

\section{Mundos Virtuais}

Em EAD, estão sendo desenvolvidos ambientes criativos e inovadores que envolvem mundos virtuais. Em sentido amplo, mundo virtual é um "universo de possíveis, calculáveis a partir de um mundo digital" [LÉVY 2010, p. 75]. Por outro lado, mundo virtual também pode ser conceituado como o ambiente onde a mensagem é um mecanismo de interação que pode ser utilizado pelo usuário para controlar uma representação de si mesmo [LÉVY, 2010].

No contexto da aprendizagem imersiva, mundo virtual é um cenário, modelado através de técnicas de computação gráfica e representado tridimensionalmente, usado para representar a parte visual de um sistema de realidade virtual [SCHLEMMER et al. 2006].

Diversos estudos têm sido desenvolvidos nas últimas décadas em que professores e instituições têm utilizado mundos virtuais para tentar tornar a aprendizagem mais relevante para os alunos, criando oportunidades para que eles possam aplicar o conteúdo ministrado em situações que se aproximem da realidade [DEDE 2009] [SCHLEMMER et al. 2006] [DE LUCIA et al. 2008]. Esses ambientes permitem, entre outras coisas, replicar salas de aula, laboratórios e demais ambientes utilizados no processo de ensino e aprendizagem, adicionando uma nova dimensão para a aprendizagem.

\subsection{Mundo Virtual Escolhido}

Foi escolhido o mundo virtual Second Life (disponível em www.secondlife.com) porque estudo comparativo [REIS et al. 2011] mostra a superioridade desta ferramenta frente as demais do mercado, no que se refere principalmente ao quesito "realismo do mundo", essencial para a construção de uma réplica que guarde fidelidade ao mundo real. O estudo utiliza fórmulas matemáticas para obter pontuações em sete categorias, a saber: realismo do mundo, interface utilizador, comunicação, avatar, escalabilidade, segurança e participantes. O Second Life mostrou maior pontuação no somatório dos itens, quando comparado com outros mundos virtuais como OpenSim e ActiveWorld. No contexto da educação, a ferramenta permite que o aluno tenha uma visão de dentro para fora, vivenciando os problemas elaborados durante o processo de ensino e aprendizagem.

\section{Processo Para Construção de Ambientes Virtuais Para Aprendizagem Imersiva}

Para a construção de um ambiente imersivo de aprendizagem, é necessário que sejam desempenhadas diversas atividades. A organização dessas atividades pode ser um fator determinante para o sucesso ou fracasso do ambiente, sobretudo levando em consideração o objetivo do ambiente construído, no caso em estudo, a aprendizagem. 
Neste sentido, propõe-se um processo para a construção de uma réplica de um ambiente real em um ambiente virtual de aprendizagem imersiva com foco na fidelidade e no realismo, cujo detalhamento será feito a partir de uma aplicação experimental.

\subsection{Ambiente replicado}

O processo foi aplicado experimentalmente na construção de uma réplica do Laboratório de Saneamento da Universidade Federal da Paraíba (UFPB). O laboratório replicado possui diversos equipamentos capazes de realizar atividades pedagógicas, sobretudo para análises de água potável e água residuária (esgoto doméstico e industrial), tais como: balanças de precisão, agitador magnético, bombas de vácuo, centrífuga, entre outros. Para garantir o máximo grau de fidelidade, esses equipamentos foram modelados dentro do Second Life.

\subsection{Atores}

Para a instanciação do processo, sugere-se a participação de pelo menos 3 atores: o desenvolvedor, que é a pessoa que tem domínio da ferramenta de construção; o usuário do mundo real, que é aquela pessoa que habita o ambiente real a ser reproduzido; e o supervisor, cuja função é desempenhar atividades inerentes à organização do processo. Opcionalmente, pode haver a participação de outras pessoas - a depender da disponibilidade do projeto - integrando a equipe de desenvolvimento.

\subsection{Etapas}

Para a construção de um ambiente imersivo de aprendizagem, é necessário que sejam desempenhadas diversas atividades. A organização dessas atividades pode ser um fator determinante para o sucesso ou fracasso do ambiente, sobretudo levando em consideração o objetivo do ambiente construído, neste caso, a aprendizagem.

O processo de construção de um ambiente para aprendizagem imersiva deve passar por algumas etapas visando a garantir o realismo do produto final (ver Figura 1).

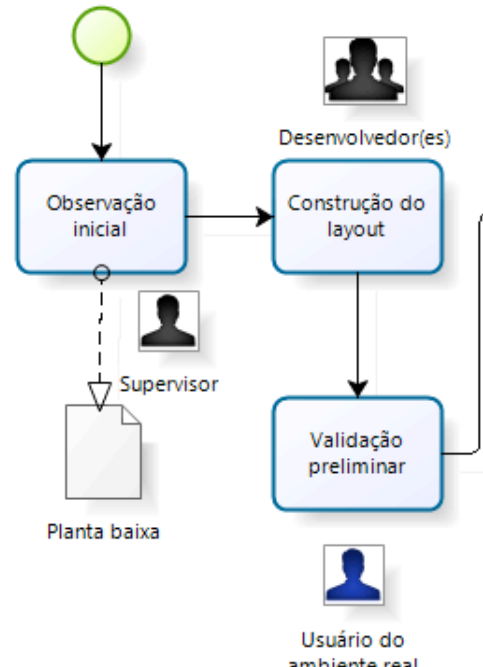

ambiente real
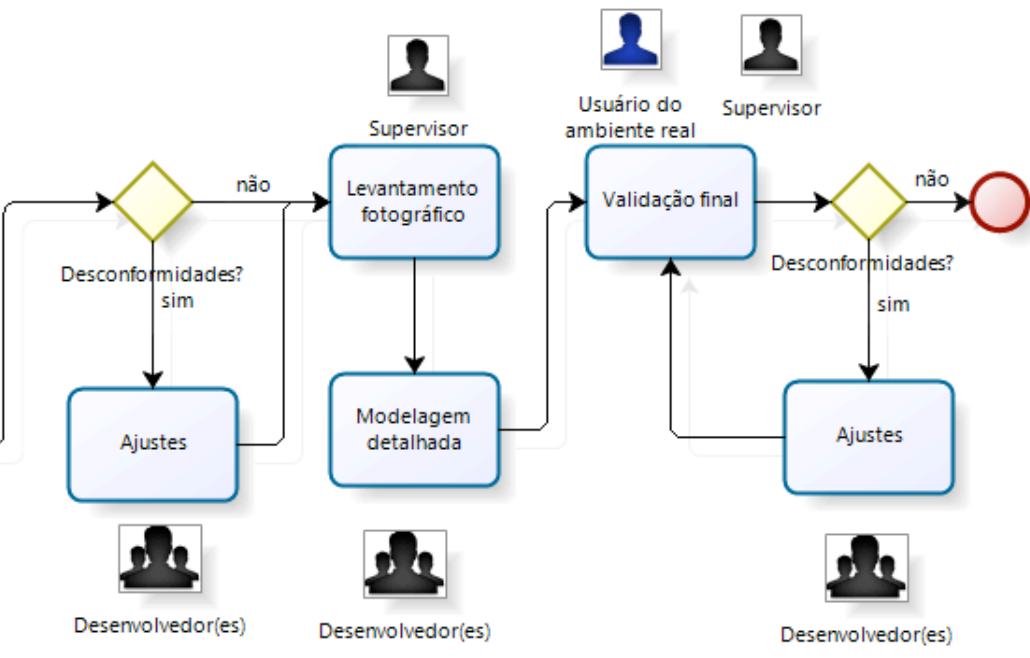

Figura 1. Etapas do processo 
O início é marcado pelas primeiras visitas do supervisor ao ambiente real que se planeja reproduzir. Nesta primeira etapa, é preciso fazer o levantamento de requisitos e analisar sobretudo os aspectos geométricos: formas, medidas e organização do espaço, por exemplo. Esta análise pode ser feita através do levantamento de medidas do ambiente combinado com um levantamento fotográfico panorâmico - neste momento, ainda sem considerar os detalhes dos equipamentos do ambiente. Como resultado, deve ser elaborada a planta baixa, para que sirva de base para a modelagem do layout.

No contexto do experimento, o início se deu com as primeiras visitas do supervisor ao Laboratório de Saneamento da UFPB. Durante uma semana, foram tiradas fotos do plano geral. Neste ponto, as visitas tinham foco no levantamento das medidas do laboratório para que os elementos construídos no Second Life guardassem fidelidade com o mundo real no que diz respeito principalmente à proporcionalidade dos espaços. Como resultado desse primeiro levantamento, construiu-se a planta baixa do laboratório.

Tomando por base o artefato construído na primeira fase do processo, qual seja, a planta baixa, deve-se seguir para a fase de construção dentro da ferramenta. Como pode ser visto na Figura 1, esta tarefa deve ser executada pelo desenvolvedor, ou seja, aquele que possui o domínio da ferramenta de construção.

No caso do experimento, partiu-se para a etapa de modelagem dentro do Second Life. Neste momento, foram construídas no ambiente virtual as bancadas e os equipamentos de grande porte (geladeiras e estufas), de acordo com a organização do layout apresentado.

Como visto, a literatura indica a fidelidade ao mundo real, isto é, quão próximo o ambiente virtual está da realidade no quesito realismo gráfico, como um dos fatores que contribuem para a melhoria da motivação do aluno em um ambiente imersivo. Portanto, é importante garantir que o ambiente a ser construído reproduza todos os aspectos visuais do ambiente real.

Neste sentido, deve-se passar por uma fase preliminar de validação da construção. Nesta fase, é essencial a atuação de um agente externo, que é a pessoa que utiliza o ambiente na vida real. Neste momento, a pessoa responsável pela validação do ambiente deve anotar as desconformidades, e, em havendo alguma característica que considere que não retrata o ambiente real, devem ser feitos os ajustes necessários antes de passar para a etapa seguinte. No contexto do experimento, a validação preliminar foi feita pelo laboratorista (técnico responsável pelo manuseio dos equipamentos do laboratório), que foi convidado a entrar no ambiente virtual para observar os espaços e fazer análise de fidelidade e proporção dos objetos construídos em relação ao laboratório real. Na ocasião, foram identificadas desconformidades em relação à proporção das bancadas, que se apresentavam maiores no ambiente virtual, oportunidade em que foram relatadas as inconformidades e feitos os ajustes para seguir para a fase seguinte do processo.

Passada a etapa de validação da construção, é preciso fazer levantamento fotográfico focando nos detalhes do ambiente e dos objetos que lá se encontram (cores, texturas). Para isso, sugere-se a adoção de equipamentos de fotografia de alta resolução, posto que quanto maior a qualidade da foto, maior a chance de reprodução dos detalhes. 
Neste ponto, importante fotografar os objetos intrínsecos, ou seja, aqueles próprios do ambiente, como também os extrínsecos, ou seja, aqueles que estão dentro do ambiente mas que não são propriamente de lá. É o caso, por exemplo, dos objetos das pessoas que habitam os ambientes, como bolsas e notebooks.

No caso do experimento, foram feitas novas visitas ao laboratório, desta vez para o levantamento fotográfico dos equipamentos expostos nas bancadas. Relativamente ao levantamento fotográfico, foi utilizada a câmera Nikon D5100 para que fossem tiradas fotos com alta resolução do ambiente real.

Passada a fase de levantamento do material fotográfico de alta resolução, deve-se seguir para a modelagem e construção em si, onde são construídos os componentes físicos do ambiente. Nesta fase, o desenvolvedor deve, de posse do material fotográfico levantado, reproduzir todos os objetos do com todos os detalhes que forem possíves. No experimento, as fotos coletadas foram inseridas no contexto da ferramenta de desenvolvimento 3D. A partir daí, foi feito o desenho de forma a sobrepor a imagem da foto. Importante ressaltar que é preciso modelar o ambiente tal qual ele se apresenta nas fotos, o que significa dizer que as imperfeições (parede suja, fios soltos) devem também ser modeladas para o ambiente virtual.

No caso do experimento, é preciso destacar a semelhança com que foram construídos no mundo virtual. A Figura 2 ilustra um destilador de nitrogênio no laboratório real (A) em comparação com o mesmo equipamento construído no ambiente virtual (B). É possível perceber, além da semelhança dos equipamentos, os detalhes como a caixa de energia ao fundo, bem como os fios soltos. O laboratório virtual construído não permitia a interação dos alunos com os equipamentos. No entanto, esta característica era pouco importante considerando a atividade a ser desempenhada no ambiente, qual seja, a análise de riscos, que compreende, basicamente, a observação de fatores que possam levar algum risco a quem habita o ambiente estudado

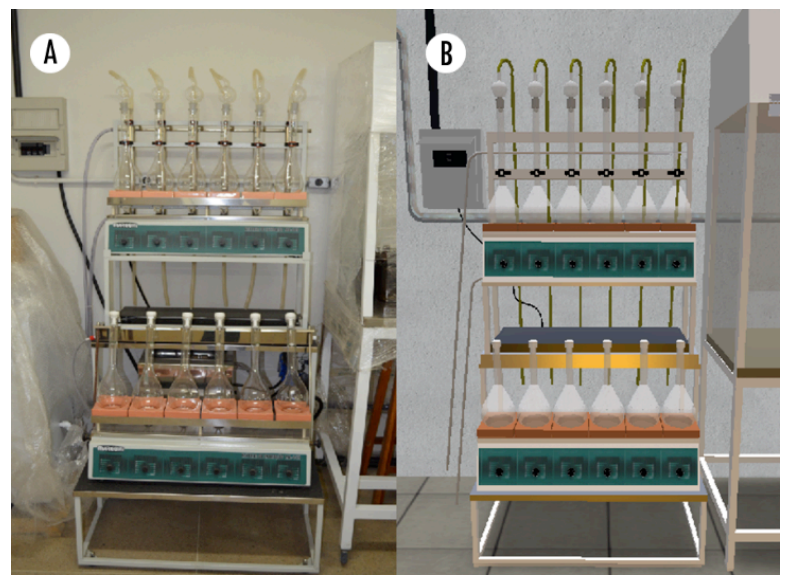

Figura 2. - Equipamento modelado (com reprodução do fio solto). (A) ambiente real. (B) ambiente virtual

A etapa seguinte do processo consiste na validação final, oportunidade em que o usuário realiza novas observações no ambiente virtual construído com o intuito de analisar 
e verificar alguma desconformidade com o ambiente real. Neste ponto, diferente da primeira validação, todos os aspectos devem ser considerados: desde a proporcionalidade dos espaços até os detalhes dos objetos. Esta validação também deve ter a participação do supervisor, que deve verificar se os requisitos coletados na primeira fase do processo estão sendo atendidos. Caso alguma desconformidade seja verificada, deve-se seguir para a etapa de ajustes para que o problema seja resolvido. Desta forma, a entrega do produto final deve ser sempre condicionada à aprovação na fase de validação.

No contexto deste trabalho, o técnico do laboratório foi mais uma vez convidado a percorrer o ambiente virtual e fazer análises sobre a fidelidade e proporcionalidade do ambiente, desta vez com foco nos equipamentos e seus detalhes. Além disso, o supervisor verificou a adequação do laboratório construído aos requisitos elencados. Neste ponto, nenhuma desconformidade foi anotada pelo técnico ou pelo supervisor, razão pela qual procedeu-se à entrega do ambiente virtual imersivo.

\subsection{Avaliação}

O ambiente construído a partir da instanciação do processo foi avaliado em uma turma do curso de Engenharia de Produção da UFPB quando da realização da atividade de mapeamento de riscos da disciplina Segurança do Trabalho. Participaram da avaliação 6 pessoas, sendo 5 alunos e 1 técnico do laboratório e foi feita uma análise qualitativa dos dados obtidos a partir dos questionários aplicados.

A característica da fidelidade ao mundo real foi relatada em dez momentos por quatro respondentes. Sobre isso, a modelagem de todos os equipamentos contribuiu para atrair a atenção dos alunos, como comprovam os depoimentos a seguir:

"O laboratório parecia bem construído e com um monte de equipamentos que existem realmente no laboratório real".

"Em se tratando do ambiente virtual, ele representa de maneira muito próxima da realidade o ambiente real".

O processo indica que devem ser construídos não somente os objetos intrínsecos, no caso do experimento, os equipamentos (estufa, geladeiras, entre outros), como também os extrínsecos, neste caso, aqueles objetos de uso cotidiano dos técnicos que utilizam o laboratório, isto é, cadernos, mochilas, computador e impressora estavam presentes também no ambiente virtual. Os detalhes também foram relatados durante o questionário, ressaltando o aspecto da fidelidade ao mundo real, como comprovam os depoimentos:

"Era tudo muito real. Até o detalhe do computador ligado e a impressora que estava na mesa do técnico... Tudo parecia real”.

"Os equipamentos pareciam mesmo de verdade... Dava para ver os detalhes de conservação deles”. 
"A gente via em detalhes os equipamentos. Teve uma hora lá que eu tive que dar um zoom pra ver melhor o equipamento... Por isso que eu relatei o risco do fio desemcapado... Porque eu consegui ver usando o zoom..."

Dados os detalhes, a fidelidade do ambiente virtual em relação ao real contribuiu para que os alunos se sentissem de fato no mundo real mesmo diante da tela de um computador.

"Me senti como se estivesse num laboratório real porque o ambiente gráfico reflete exatamente um ambiente real. É impressionante a semelhança com o mundo real".

Além dos equipamentos, a estrutura em si do laboratório também foi replicada, o que refletiu na análise dos alunos no que diz respeito à conservação e à limpeza do ambiente, fatores importantes que devem ser considerados na atividade desenvolvida.

"Dava pra ver que tinha alguns que estavam precisando de manutenção... Ou até de limpeza mesmo... Dava até pra ver o 'remendo' do ar-condicionado e uns fios soltos".

Ainda no que diz respeito à motivação, um respondente relata ter sido a experiência mais motivadora em comparação com uma atividade presencial em função dos recursos gráficos proporcionados pelo mundo virtual.

“Às vezes numa aula normal a gente fica 'voando' ... Agora não... Eu prendi mais minha atenção porque eu estava vendo as coisas em $3 D$.

\section{Conclusões}

O desenvolvimento da tecnologia da informação tem como consequência mudanças cada vez mais rápidas. No contexto da Educação, a informática desempenha papel importante na medida em que serve como meio para fornecer oportunidades educacionais, sobretudo na EAD. Além disso, novas tecnologias podem ser aplicadas para superar os problemas enfrentados em cursos dessa modalidade.

A construção de um ambiente imersivo em um mundo virtual requer que sejam seguidas várias etapas, desde o primeiro levantamento até a entrega do produto final. Neste contexto, é preciso seguir regras visando garantir as características de imersão, sobretudo no que se refere à fidelidade em relação ao ambiente real.

Neste sentido, este trabalho contribuiu com a criação de um processo para criação de um ambiente imersivo, visando garantir o realismo do ambiente virtual. Portanto, esta pesquisa descreveu um modelo para a construção de uma réplica de um ambiente real em um mundo virtual voltado para a aprendizagem imersiva. O processo foi instanciado com a construção de um laboratório imersivo no mundo virtual Second Life. A partir do ambiente construído, foi feito um experimento, que analisou especificamente o quesito fidelidade ao mundo real como característica motivadora no uso do ambiente. 
Os resultados mostraram indícios de que o laboratório construído a partir do processo descrito guarda fidelidade com o mundo real, e, como consequência, ajuda a na motivação do aluno no processo de ensino e aprendizagem.

\section{Referências}

BARATA, M. A Motivação para a Aprendizagem em Crianças do $1^{\mathrm{o}}$ ano de Escolaridade. Dissertação de Mestrado. Lisboa: Instituto Superior de Psicologia Aplicada, 2006.

CENSOEAD.BR. Associação Brasileira de Educação a Distância. São Paulo: Pearson, 2013.

CHENEY, Amelia; SANDERS, Robert L. Teaching and learning in 3D immersive worlds: pedagogical models and constructivist approaches. Hershey: Information Science Reference, 2011.

CLARK, Ruth Colvin. Evidence-Based Training Methods: A Guide for Training Professionals. Alexandria: ASTD Press, 2010.

CSIKSZENTMIHALYI, Mihaly; NAKAMURA, Jeanne. Flow Theory and Research. In: LOPEZ, Shane; SNYDER, C. R. Oxford Handbook of Positive Psychology. Nova Iorque: Ofxord University Press, 2009.

DEDE, Chris. Immersive Interfaces for Engagement and Learning. Science Magazine. V. 323, p. 66-69, jan/2009.

DE FREITAS, Sara; OLIVER, Martin. How can exploratory learning with games and simulations within the curriculum be most effectively evaluated? Computers and Education, Special Issue. 46 249-264. 2006.

DE LUCIA, Andrea; FRANCESE, Rita; PASSERO, Ignazio; TORTORA, Genoveffa. Development and evaluation of a virtual campus on Second Life: The case of SecondDMI. Computers \& Education, 2008.

LÉVY, Pierre. Cibercultura. Tradução de Carlos Irineu da Costa. 2 ed. São Paulo: Trinta e quatro, 2010.

REIS, Rosa; FONSECA, Benjamin, ESCUDEIRO, Paula. Comparative Analysis of Virtual Worlds. In: Information Systems and Technologies at Iberian Conference, 2011.

SCHLEMMER, Eliane; BACKES, Luciana; FRANK, Patrícia Silva Smurra; Da SILVA, FREDERICO Andros; Del SENT, Deise Tavares. EcoDI: A criação de um Espaço de Convivência Digital Virtual. In: XVII Simpósio Brasileiro de Informática na Educação SBIE - UNB/UCB. 2006. P. 467-477.

SHERMAN, William; CRAIG, Alan. Understanding Virtual Reality: Interface, Application and Design. San Francisco: Morgan Kayfmann, 2003.

SLATER, M.; WILBUR, S. A Frame for Immersive Virtual Environments (five): Speculations on the Role of Presence in Virtual Environments. Presence: Teleoperators and Virtual Environments, v. 6, p. 603-616, 1997. 